\title{
Cenozoic Antarctic DiatomWare/BugCam: An aid for research and teaching
}

Wise, S. W., ${ }^{1}$ M. Olney, ${ }^{1}$ J. M. Covington, ${ }^{2}$ V. M. Egerton, ${ }^{1}$ S. Jiang, ${ }^{1}$ D. K. Kulhanek ${ }^{1}$ S. Ramdeen, ${ }^{1}$ H. Schrader, P. A. Sims, ${ }^{3}$ A. S. Wood, ${ }^{1}$ A. Davis, ${ }^{1}$ D. R. Davenport, ${ }^{1}$ N. Doepler, ${ }^{1}$ W. Falcon, ${ }^{1}$ C. Lopez, ${ }^{1}$ T. Pressley, ${ }^{1}$ O. L. Swedberg, ${ }^{1}$ D. M Harwood ${ }^{4}$

${ }^{1}$ Department of Geological Sciences, Florida State University, Tallahassee, FL 32306-4100, USA (wise@gly.fsu.edu)
2BugWare, Inc., 4027 Bobbin Brook East, Tallahassee, FL 32312 (mitch.covington@bugware.com)
${ }^{3}$ Botany Department, Natural History Museum, Cromwell Road, London, SW7 5BD, UK.
${ }^{4}$ Department of Geosciences, University of Nebraska-Lincoln, Lincoln, NE 68588-0340 USA (dharwood1@unl.edu)

\begin{abstract}
Cenozoic Antarctic DiatomWare/BugCam ${ }^{\circ}$ is an interactive, icon-driven digital-image database/software package that displays over 500 illustrated Cenozoic Antarctic diatom taxa along with original descriptions (including over 100 generic and 20 family-group descriptions). This digital catalog is designed primarily for use by micropaleontologists working in the field (at sea or on the Antarctic continent) where hard-copy literature resources are limited. This new package will also be useful for classroom/lab teaching as well as for any paleontologists making or refining taxonomic identifications at the microscope. The database (Cenozoic Antarctic DiatomWare) is displayed via a custom software program (BugCam) written in Visual Basic for use on PCs running Windows 95 or later operating systems. BugCam is a flexible image display program that utilizes an intuitive thumbnail "tree" structure for navigation through the database. The data are stored on Micrsosoft EXCEL spread sheets, hence no separate relational database program is necessary to run the package.
\end{abstract}

Citation: Wise, S. W., M. Olney, J. M. Covington, V. M. Egerton, S. Jiang, et al. (2007), Cenozoic Antarctic DiatomWare/BugCam: An aid for research and teaching - Online Proceedings of the $10^{\text {th }}$ ISAES, edited by A. K. Cooper and C. R. Raymond et al., USGS Open-File Report 2007-1047, Short Research Paper 017, 4 p.; doi:10.3133/of2007-1047.srp017.

\section{Introduction}

Diatoms (Sims, et al., 2006) are arguably the most important microfossil group used today in the study of Antarctic Cenozoic marine deposits from the nearshore to the deep sea, particularly those of Neogene age south of the present-day Antarctic Polar Front. Depth habitats of these organisms are restricted to within the euphotic zone. Summaries of the literature for Antarctic Cenozoic diatoms, their geographic distribution, biostratigraphy, and taxonomy are provided by Harwood and Maruyama (1992) and Ramsay and Bauldauf (1999).

These microfossils have great biostratigraphic importance in the Southern Ocean as they are often highly abundant and their stratigraphic ranges tend to be relatively short. In addition, paleoclimatic and paleoceanographic studies increasingly rely on fossil diatom data. Changing biogeographic distributions of given taxa indicate shifting paleoecological conditions and provide evidence of the surface productivity and temperatures of ancient oceans. The generality of conclusions, though, is limited by variations in species concepts among the relatively small numbers of diatom specialists that work in this region. The situation is further complicated by the fact that diatoms tend to be provincial in their distribution, particularly when compared to the calcareous microplankton, hence different oceanic realms have their own particular mix of diatom species and assemblages. The broad research community, however, relies directly or indirectly on the accurate identification of diatom species.

During the past two decades, significant revisions of diatom taxonomy, classification, and biostratigraphy have been published (e.g., Akiba and Yanagisawa 1986;
Round, et al., 1990; Nikolaev and Harwood, 2000; Cersarek and Gersonde, 2002; Zerlinski and Gersonde, 2002). The taxonomy has undergone major revison due to the impact of the scanning electron micrsocope, which is now used routinely to resolve ultrastructural features of valve morphology (Round et al., 1990). The biostratigraphy has been revised considerably due to the continued exploration of the ocean basins by scientific drilling (Intergrated Ocean Drilling Project and its predecessors [http://www.iodp.org/]) and, in the Antarctic, ship- and ice-based drilling projects such as the Cape Roberts Project (1997-1999; www.geo.vuw.ac.nz/croberts), $\quad$ SHALDRIL (http://www.arf.fsu.edu/projectsShaldril.cfm), and ANDRILL Projects (http://andrill.org). These revisions, however, are scattered in the literature, and the most recent comprehensive guides for fossil diatoms (Barron, 1985; Fenner, 1985) are themselves over 20 years old.

Fortunately, current technology can facilitate access to standard references needed to make accurate identifications, even in remote locations. The potential for widespread use of computerized taxonomic identification databases has increased considerably as a result of advances in digital imaging technology, software, and storage along with a reduction in the cost of the supporting hardware. Vast amounts of data in the form of digital images or text can be accessed rapidly and relatively inexpensively by a wide range of researchers in the scientific community. Efforts to capture and organize text and digital image data, however, have not kept up with the technological and computer programming advances in many areas of micropaleontology. Particularly needed for work in 
remote areas of the high southern latitudes is an interactive image database of Cenozoic Antarctic diatoms that can be accessed from CD-ROMs and, if available, the Internet.

\section{The Cenozoic Antarctic DiatomWare/BugCam Package}

We have developed an interactive, icon-driven digital-image catalog of modern and fossil Cenozoic diatoms from the Southern Ocean for use by specialists as an aid for rapid, accurate, and consistent species identification. It is especially useful where it is not possible to maintain standard library resources such as onboard research vessels or at research bases in the Antarctic. At sea, SHALDRIL has proven the feasibility of placing a diamond coring system on an ice-breaking research vessel for work along the Antarctic continental margins and inland seas (Anderson, et al., 2006), whereas ANDRILL has recovered an unprecidented $1285 \mathrm{~m}$ of Neogene sediment via ice-based coring (West, 2007). All of these initiatives rely heavily on diatom biostratigraphy to achieve their research objectives.

Our database, Cenozoic Antarctic DiatomWare, contains over 500 species representing over 100 genera. It is run by a custom software program called "BugCam" written and adapted by one of us (J. Mitchener Covington). The database/software package can be accessed from CD-ROMs on IBM-compatible Windows platforms or on Macintosh computers using appropriate conversion programs. The images have been obtained by scanning photographs or sketches of holotypes, paratypes, and hypotypes selected from the literature or the Internet, by capturing original digital lightmicroscope images from our own research collections, and by direct digital output of an SEM. The text has been scanned from published descriptions or keyed in manually as necessary. The data fields can be accessed through Microsoft EXCEL sheets by the click of a mouse button, hence no relational database is necessary to run the package.

We have modelled this DiatomWare/BugCam package after our previous product called "Cenozoic NannoWare” (Wise et al., 2004), three editions of which have been distributed at a nominal cost by the International Nannoplankton Association (INA; http://www.nhm.ac.uk/hosted_sites/ina/announce/INAC Dv3.htm) over the past five years. The DiatomWare/BugCam package will also be distributed initally by INA beginning in the fall of 2007; eventually the database will also be available on the internet.

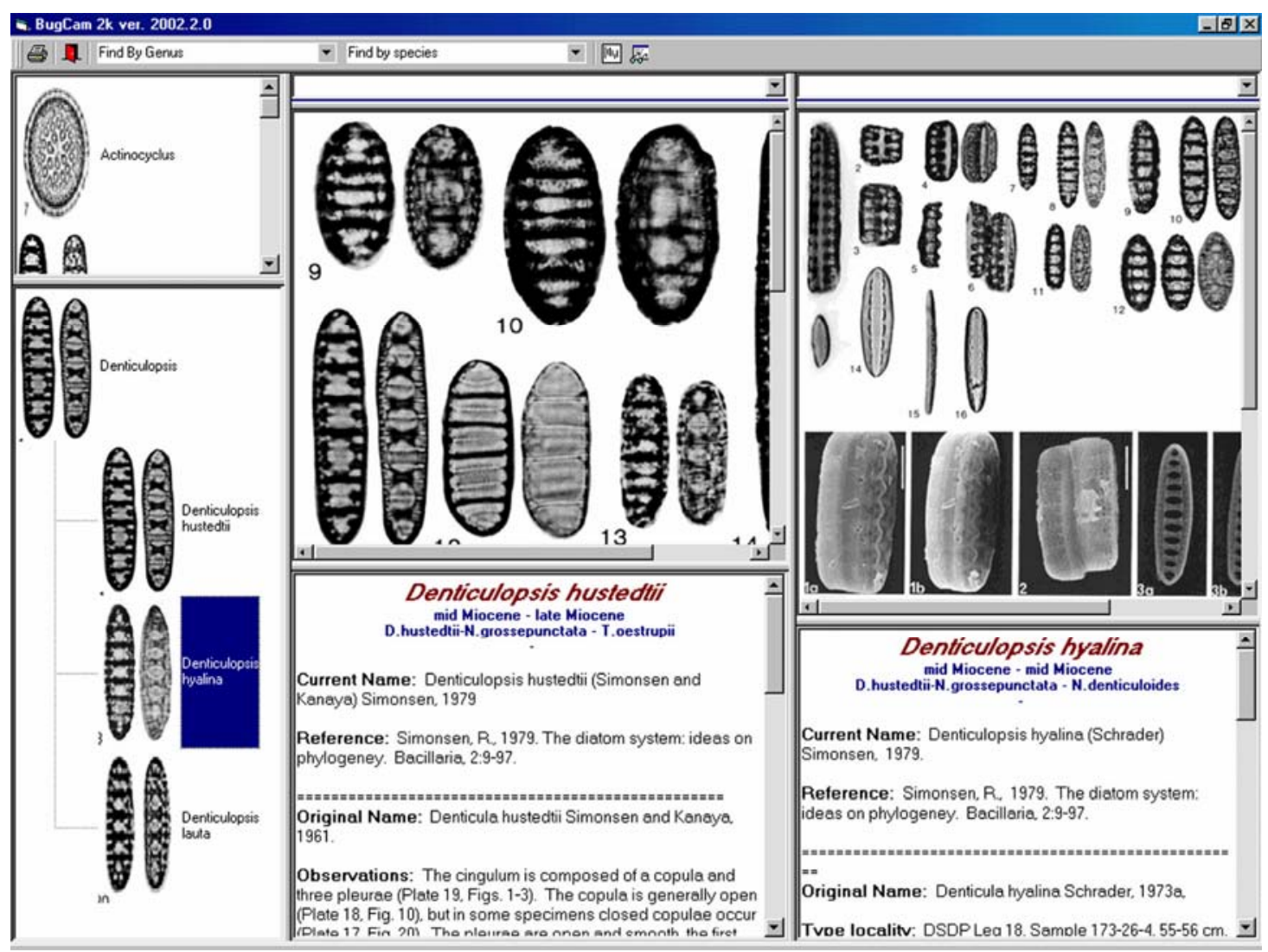

Figure 1. Sample of what the DiatomWare/Bugcam interface looks like with the Family-Genus-Species "tree" of thumbnail icons open in sliding frames on the left and two of the species "taxa" frames open on the right for comparison. All frame bars are moveable to allow for the adjustment of the size of each frame. 


\section{How the DiatomWare/BugCam Package Works}

BugCam is a flexible fossil-image display program that utilizes an intuitive photo-thumbnail "tree" structure for navigation through the fossil database. As shown in Figure 1, this "tree" operates much like the hierarchical file directory used in Windows.

The first level of the tree contains thumbnail images of some 20 families or family groups (Fig. 1, upper left panel). Clicking the mouse on one of the family-group icons displays on the same screen thumbnail images of all of the genera within that group, whereas clicking on one of the generic thumbnails displays all of the species thumbnail-images within that genus. This is illustrated in the lower left panel in Figure 1, which shows the genus Denticulopsis and three of its species (D. hustedii, $D$. hyalina, and D. lauta). All of the images at any level are displayed on a sliding "window pane" so that one can quickly scan all of the genera or species within any family group. In this way the user can quickly sort out (or "key down") an unknown specimen seen in the microscope in order to identify it down to species and to determine its age.

In addition to the 3-level "tree" of thumbnails, complete records for any two species can be displayed simultaneously and compared on the same screen as illustrated in the two right-hand panels in Figure 1, where Denticulopsis hustedii and D. hyalina can be viewed side-by-side. Displayed for each species are a composite of illustrations including light and electron micrographs and a good drawing if available, including that of the holotype; light micrographs usually include plain-transmitted and, where possible, differential interference contrast (DIC) images. A "blow-up" feature allows many of the images to be viewed in greater detail at higher magnifications.

Along with the original text descriptions, we often provide an English 35-word or less "mini-description" that gives in a nut shell the current concept of the taxon. These are crucial for the smooth and quick operation of the program because many of the original descriptions are in a number of different languages (mostly English, German, French, Japanese, and Russian) and some can run on for pages. Also given are the age range for the taxon and a list of similar species. If the investigator is still in doubt about the identification, up to 4 similar species can be called up from a pop-down list and displayed in turn on the screen.

\section{Scale and Scope}

Stratigraphically, the taxonomic database spans the time interval from the Cretaceous/Tertiary boundary to the Recent. Biogeographic coverage lies within the present-day Southern Ocean, extending from the interior seas and continental shelf of Antarctica to the deep sea as far north as the Subtropical Front, which separates surface waters originating in the tropics from those of
Antarctic origin (see Belkin and Gordon, 1996). The entire DiatomWare/BugCam package occupies approximately $100 \mathrm{Mb}$ of hard drive disk space. In the field, it can be run on a notebook computer.

\section{Discussion}

Our ultimate goal in developing the DiatomWare/BugCam package is to provide a useful tool for the research community, although we believe it will have useful applications at various levels for teaching as well. It is designed to provide a rapid and efficient means for species identification, minimizing the need for literature searches for various species descriptions, illustrations, and distributional information. We hope that:

(1) The taxonomic, biostratigraphic, and biogeographic information will be updated and stay current by continual addition of information as it becomes available from the research community;

(2) It will promote uniformity based on the opinions of leading experts in the field;

(3) It will thereby stimulate efforts to resolve outstanding taxonomic inconsistencies and will focus attention on lineages whose phylogenies are poorly understood.

(4) It will provide a means of passing on taxonomic knowledge from one generation of diatom experts to another;

(5) It will be operable at remote Antarctic research stations, ships and facilities that have standard computer access but inadequate hard-copy literature.

(6) It will have useful educational value and application. Diatom/Ware can be used at various levels of the educational system, such as in secondary schools to demonstrate the Linnean binomial nomenclature and system of classification, in undergraduate training to introduce diatoms in introductory paleontology classes (diatoms are a fossil group traditionally under-represented in such classes), and at the graduate level to aid in the training of future specialists in Antarctic diatoms.

Acknowledgments. We thank our co-editor/refereer, John Barron, and referee, Lloyd Burckle, for their helpful reviews of the manuscript, and our many colleagues among the diatom community who have contributed in innumerable ways to the compilation of the database. To date, the diatom taxonomy has been done by Olney, Wise, Sims, Kulhanek, Schrader, and Harwood, but additional contributions from the user community will be gratefully accepted by Wise, who will be responsible for periodic updates in the future. We are also grateful to Dr. Jeremy Young who kindly supervised one of us (S. Ramdeen) during her gradaute internship at the British Natural History Museum, where she transcribed many of the older literature sources with the aid of Dr. Sims. The project was supported by NSF grant OPP-0230469 to SWW.

\section{References}

Anderson, J. B., J. S. Wellner, S. Bohaty, P. L. Manley, S. W. Wise, Jr. (2006), Antarctic Shallow Drilling Project Provides Key Core Samples, Eos Trans. AGU, 87(39), 402, 10.1029/2006EO390003. 
Akiba, F., and Y. Yanagisawa (1986), Taxonomy, morphology and phylogeny of the Neogene diatom zonal marker species in the middle-to-high latitudes of the North Pacific, in H. Kagami, D. E. Karig, W. T. Coulbourn, W. T. et al., Init. Repts. DSDP, Washington (U.S. Govt. Printing Office), 87, 483-554.

Barron, J. A. (1985), Miocene to Holocene planktic diatoms, in Plankton Stratigraphy, edited by H. M. Bolli, J. B. Saunders, and K. Perch-Nielsen K., pp. 763-809, Cambridge University Press.

Belkin, I M., and A. L. Gordon (1996), Southern Ocean fronts from the Greenwich meridian to Tasmania, J. Geophys. Res., 101, 3675-3696.

Cersarek, B., and R. Gersonde (2002), Miocene diatom biostratigraphy at ODP Sties 689, 690, 1088, 1092 (Atlantic sector of the Southern Ocean), Mar. Micropaleontol., 45, 309-356.

Fenner, J. (1985), Late Cretaceous to Oligocene planktic diatoms, in Plankton Stratigraphy, edited by H. M. Bolli, J. B. Saunders, and K. Perch-Nielsen K., Cambridge University Press, pp. 713-762.

Harwood D.M. and T. Maruyama (1992), Middle Eocene to Pleistocene diatom biostratigraphy of Southern Ocean sediments from the Kerguelen Plataeu, Leg 120, in S. W. Wise Jr., R. Schlich et al., Proc. ODP, Sci. Results, College Station, TX, Ocean Drilling Program, 120(2), 683-733.

Nikolaev, V. A, and D. M. Harwood (2000), Diversity and system of classification in centric diatoms, in The origin and early evolution of the diatoms: fossil, molecular and biogeographical approaches, edited by A. Witkowski and J. Siemimska, pp 37-53, W. Szafer Institute of Gotany, Polish Academy of Sciences, Cracow.

Ramsay A.T.S. and J. G. Baldauf J.G. (1999), A Reassessment of the Southern Ocean Biochronology. Geol. Soc., London, Mem. 18, 122 pp.

Round, F. R., R. M. Crawford, and D. G. Mann (1990), The Diatoms. Cambridge University Press, Cambridge, 747 pp.

Sims, P. A., D. G., Mann, D. G., and L. K. Medlin (2006), Evolution of the diatoms: Insights from fossil, biological and molecular data, Phycologia, 45, 361-402.

West, P. (2007), School of Rock, Nature, 446, 129-131.

Wise, S. W., J. M. Covington, B. C. Ladner, and W. Wei, W. (Compilers) (2004), Electronic Calcareous Nannofossils, Version 3. International Nannoplankton Association, CD-ROM Series, No. 1.

Zielinski, U. and R. Gersonde (2002), Plio-Pleistocene diatom biostratigraphy from ODP Leg 177, Atlantic sector of the Southern Ocean, Mar. Micropaleontol., 45, 225-268. 